\title{
Processing Food ...Decreases or Increases Nutritive Value?
}

\section{Aradhana Dixit*}

Department of Food and Nutrition, India

*Corresponding Author: JAradhana Dixit, Department of Food and Nutrition, India.

Received: August 27, 2019; Published: September 06, 2019

"Every time you process food there are some nutrient losses".

What is food processing?

In food processing fresh food is converted into a product.

Food processing is done to

- Increase life of food

- $\quad$ Fortifying food i.e. adding nutrients

But by food processing generally the nutritional quality of food is maintained or rather increased.

- $\quad$ There are definitely losses when a food is processed...for example when meat is cooked there are losses of vitamin A.

- $\quad$ Though there is little or no effect on vitamin D,E and K.

- Most of the cooking methods are same relatively but maximum losses are seen in boiling.

- Is food processing than good or bad??

- Processing any natural food is not good until nutritional quality is maintained or increased.

- In plant based food cooking or overcooking may cause loss of vitamin $\mathrm{C}$ and foliate.

While processing food it undergoes...

- $\quad$ Freezing

- $\quad$ heating and reheating

All steps take you away from natural taste of your food.

Whether to consume than raw or cooked foods?

Both have their merits and demerits.
Demerits we have discussed but merits are that cooking makes some foods more palatable and so acceptable. cooking ills microorganisms specially in meats and poultry.

So ...processing has benefits as well as demerits.

Process ...consciously. don't overcook. but cook so that you can enjoy both nutritionally as well as palatabily!!!

Volume 3 Issue 10 October 2019

(C) All rights are reserved by Aradhana Dixit. 